\title{
A Proposal of the European Association for the Study of Obesity to Improve the ICD-11 Diagnostic Criteria for Obesity Based on the Three Dimensions Etiology, Degree of Adiposity and Health Risk
}

\begin{abstract}
Johannes Hebebrand ${ }^{a}$ Jens-Christian Holm ${ }^{b, c}$ Euan Woodward ${ }^{d}$ Jennifer Lyn Baker ${ }^{\text {ef }}$ Ellen Blaak ${ }^{g}$ Dominique Durrer Schutz ${ }^{\text {h }}$ Nathalie J. Farpour-Lambert ${ }^{i}$ Gema Frühbeck $^{j}$ Jason G.C. Halford ${ }^{k}$ Lauren Lissner $^{l}$ Dragan Micic $^{m}$ Dana Mullerovan ${ }^{n}$ Gabriela Roman ${ }^{\circ}$ Karin Schindler $^{p}$ Hermann Toplak ${ }^{q}$ Tommy L.S. Visscher ${ }^{r}$ Volkan Yumuk $^{s}$

a Department of Child and Adolescent Psychiatry, Psychosomatics and Psychotherapy, University Hospital Essen, University of Duisburg-Essen, Essen, Germany; ${ }^{b}$ The Children's Obesity Clinic, Department of Pediatrics, Copenhagen University Hospital Holbæk, Holbæk, Denmark; ' Novo Nordisk Foundation Center for Basic Metabolic Research, Section of Metabolic Genetics, University of Copenhagen, Copenhagen, Denmark; ${ }^{d}$ European Association for the Study of Obesity (EASO), Middlesex, UK; e Department of Clincal Epidemiology, Bispebjerg and Frederiksberg Hospital, The Capital Region, Copenhagen, Denmark; ${ }^{f}$ Novo Nordisk Foundation Center for Basic Metabolic Research, Faculty of Health and Medical Sciences, University of Copenhagen, Copenhagen, Denmark; 9 Department of Human Biology, NUTRIM, School for Nutrition and Translational Research in Metabolism, Maastricht University, Maastricht, The Netherlands; ${ }^{h}$ Service d'enseignement thérapeutique pour maladies chroniques, Département de médecine communautaire, Hôpitaux Universitaires de Genève, Genève/Eurobesitas COMs Center, Vevey, Switzerland; iService d'enseignement thérapeutique pour maladies chroniques. Département de médecine communautaire, de premier recours et des urgencies. Hôpitaux Universitaires de Genève, Geneva, Switzerland; 'Department of Endocrinology \& Nutrition, Clínica Univ. de Navarra, IdiSNA, CIBEROBN, Spanish Health Institute Carlos III, Pamplona, Spain; ${ }^{k}$ Department of Psychological Sciences, Institute of Psychology, Health and Society, University of Liverpool, Liverpool, UK; ' Section for Epidemiology and Social Medicine (EPSO), Institute of Medicine, Sahlgrenska Academy, University of Gothenburg, Gothenburg, Sweden; ${ }^{m}$ Faculty of Medicine, University of Belgrade, Belgrade, Serbia; ${ }^{n}$ Department of Public Health and Preventive Medicine, Faculty of Medicine in Pilsen, Charles University, Pilsen, Czech Republic; 'Faculty of Medicine, 'Iuliu Hatieganu' University of Medicine and Pharmacy, Clinical Center of Diabetes, Nutrition, Metabolic Diseases, Cluj-Napoca, Romania; ${ }^{P}$ Division for Endocrinology and Metabolism, Medical University Vienna, Vienna, Austria; ${ }^{9}$ Department of Internal Medicine, Medical University of Graz, Graz, Austria; ${ }^{r}$ Research Center for Healthy Cities, Windesheim University of Applied Sciences, Zwolle, The Netherlands; ${ }^{5}$ Division of Endocrinology, Metabolism and Diabetes, Department of Medicine, Istanbul University Cerrahpasa Medical Faculty, Istanbul, Turkey
\end{abstract}

Prof. Dr. Johannes Hebebrand

Department of Child and Adolescent Psychiatry, Psychosomatics and Psychotherapy University Hospital Essen, University of Duisburg-Essen

Wickenburgstraße 21, 45147 Essen, Germany

johannes.hebebrand@uni-due.de 


\title{
Keywords
}

ICD-10 · ICD-11 · Obesity class · Overweight · Pre-obesity · Diagnostic classification

\begin{abstract}
Diagnostic criteria for complex medical conditions caused by a multitude of both genetic and environmental factors should be descriptive and avoid any attribution of causality. Furthermore, the wording used to describe a disorder should be evidence-based and avoid stigmatization of the affected individuals. Both terminology and categorizations should be readily comprehensible for healthcare professionals and guide clinical decision making. Uncertainties with respect to diagnostic issues and their implications may be addressed to direct future clinical research. In this context, the European Association of the Study of Obesity (EASO) considers it an important endeavor to review the current ICD-11 Beta Draft for the definition of overweight and obesity and to propose a substantial revision. We aim to provide an overview of the key issues that we deem relevant for the discussion of the diagnostic criteria. We first discuss the current ICD-10 criteria and those proposed in the ICD 11 Beta Draft. We conclude with our own proposal for diagnostic criteria, which we believe will improve the assessment of patients with obesity in a clinically meaningful way.

(C) 2017 The Author(s)

Published by S. Karger $\mathrm{GmbH}$, Freiburg
\end{abstract}

\section{Key Issues Relevant for the Delineation of Diagnostic Criteria for Obesity}

The discussion and delineation of the diagnostic criteria for obesity requires a brief look at key issues to provide a background for the discussion of both the classification and wording of the ICD-10 and ICD-11 Beta Draft with respect to obesity [1]. We have identified six main overarching key issues that we address for this purpose. For obvious reasons, the respective issues can only be addressed in a cursory manner; however, their focused delineation enables the reader to follow up our appraisal of the current status of the diagnostic criteria for obesity.

\section{Definition of Obesity and Body Weight Categories}

The World Health Organization (WHO) [2] defines obesity as 'a condition of abnormal or excessive fat accumulation in adipose tissue, to the extent that health may be impaired'. This definition linking abnormal or excessive fat accumulation with (potential) health impairment is at the core of the diagnostic uncertainties with respect to obesity. For one, abnormal or excessive fat accumulation is not specified or quantified; the use of the term abnormal can be perceived as being judgmental. Second, the terms fat and adipose tissue misleadingly portray the notion that both form a uniform mass. However, adipocytes in different regions and depots of the body are differentially regulated and fulfill different functions, some of which are beneficial, some of which are detrimental to health. The distinctions between brown and white adipocytes, between ectopic and non-ectopic and between visceral and subcutaneous adipose tissue readily serve to illustrate the functional/metabolic/endocrine/developmental/cellular heterogeneity inherent to both adipocytes and adipose tissue accumulation. The complexity is compounded by the influence of age, gender, ethnicity, individual genetic and environmental factors. Third, the wording 'to the extent that health may be impaired' does not address how the link between abnormal or excessive fat accumulation and health is to be assessed.

Which health aspects are relevant for the establishment of this link? According to the WHO [3], health is a state of complete physical, mental and social well-being, and not merely 
Hebebrand et al.: A Proposal of the European Association for the Study of Obesity to Improve the ICD-11 Diagnostic Criteria for Obesity Based on the Three Dimensions Etiology, Degree of Adiposity and Health Risk

the absence of disease or infirmity. However, to state that any physical, mental or social ailment associated with obesity qualifies obesity as a disease is not particularly helpful for clinicians who seek to narrow down the number of diseases/ailments that need to be screened for in any given patient; such a statement negates the clinical value of research to detect the mechanisms linking obesity to other diseases. Whereas indeed numerous mental and physical diseases have been determined to be associated with obesity, we posit that a physician should make use of this knowledge and assess a patient with obesity accordingly by e.g. knowing what comorbid disorders and what associated risk factors should be screened for in any individual patient of a given age, sex, ethnicity, family history, and personal medical history. Importantly, more than two-thirds of deaths related to a high BMI are due to cardiovascular disease [4]. Finally, the definition does not require that health is currently impaired, 'may' indicates that an abnormal or excessive fat accumulation can represent a risk factor endangering future health. The removal of the word 'may' has been suggested to indeed qualify obesity as a disease [5].

Based on the substantial correlation between BMI and fat mass upon assessment of a representative population sample, BMI $\left(\mathrm{kg} / \mathrm{m}^{2}\right)$ is widely used to assess adiposity. Paradoxically, the major limitation of the index is that it cannot distinguish fat from fat-free mass nor medically benign from medically harmful fat at the individual level. Over a wide range of the BMI distribution the BMI does not allow any conclusion as to its implications for health of the respective individual. As with many dimensional phenotypes, the extremes at both sides of the BMI distribution are of obvious medical concern including e.g. states of starvation such as those related to famines, anorexia nervosa, and disease-related cachexia/emaciation on the left and class III obesity (BMI $\geq 40 \mathrm{~kg} / \mathrm{m}^{2}$ ) at the right end.

The definitions and classifications of body weight categories have changed over time [6]. The currently widely used weight classification of the WHO [2] is based on the same BMI thresholds for adult males and females. Overweight is defined as a BMI equal to or in excess of BMI of $25 \mathrm{~kg} / \mathrm{m}^{2}$ and includes pre-obesity $\left(25\right.$ to $\left.<30 \mathrm{~kg} / \mathrm{m}^{2}\right)$ and obesity $\left(\geq 30 \mathrm{~kg} / \mathrm{m}^{2}\right)$; obesity in turn is subdivided into classes I ( 30 to $\left.<35 \mathrm{~kg} / \mathrm{m}^{2}\right)$, II $\left(35.0\right.$ to $\left.<40 \mathrm{~kg} / \mathrm{m}^{2}\right)$ and III $\left(\geq 40 \mathrm{~kg} / \mathrm{m}^{2}\right)$. However, the definition of overweight is not used consistently. Unfortunately, the WHO Beta-Draft of ICD-11 [7] and others define overweight as the weight category encompassing the BMI range between 25 and $<30 \mathrm{~kg} / \mathrm{m}^{2}$. Importantly, standard BMI groupings should be used to avoid problems of ad hoc and post hoc category selection and to facilitate between-study comparisons [8] in order to assess the risks associated with specific body weight categories.

Overweight as defined via a BMI $\geq 25 \mathrm{~kg} / \mathrm{m}^{2}$ [2] occurs in more than $50 \%$ of most European and the US adult populations; obesity (BMI $\geq 30 \mathrm{~kg} / \mathrm{m}^{2}$ ) prevalence rates are in the magnitude of $20-30 \%$ in most (post)industrialized countries and also affect a substantial proportion of the populations of developing countries. Global adult obesity rates have doubled between 1980 and today [9]: More than 1.9 billion adults ( $\geq 18$ years) were overweight in 2014 , accounting for $39 \%$ of all adults. Of these, over 600 million were obese $13 \%$ of the world population). Alarmingly, rates have approximately tripled in youth and young adults, thus entailing a high risk for increased cumulative incidences of type 2 diabetes, hypertension, and chronic kidney disease [4]; currently the worldwide obesity prevalence among children is $5 \%$ [ 4$]$.

In conclusion, BMI is widely used to indirectly assess adiposity. However, over a wide BMI range the health implications of the BMI of a particular individual cannot be fathomed without further medical assessments. For this very reason, EASO has suggested to move beyond BMI [10] and to personalize risk assessment. We nevertheless acknowledge the use of an operational BMI threshold (i.e., $30 \mathrm{~kg} / \mathrm{m}^{2}$ in Caucasian populations; other ethnicities may have lower thresholds due to increased risks for diseases associated with an excessive 
Hebebrand et al.: A Proposal of the European Association for the Study of Obesity to Improve the ICD-11 Diagnostic Criteria for Obesity Based on the Three Dimensions Etiology, Degree of Adiposity and Health Risk

fat mass) as an indicator of increased health risks; such a threshold should alert the physician to definitely pursue further medical assessments within the context of the somatic and psychological risks inherent to obesity. We also acknowledge that an individual with a BMI $\geq$ $30 \mathrm{~kg} / \mathrm{m}^{2}$ can be healthy and fit; due to elevated health risks such an individual should be monitored specifically for the development of obesity-related risk factors and diseases. The delineation of a BMI threshold entails the disadvantage that individuals with a BMI below the threshold will not be assessed in a similarly focused manner; a subgroup of these individuals may have elevated health risks and/or disease related to an elevated adiposity [4]. Thus, physicians definitely need to medically assess individuals with a BMI $<30 \mathrm{~kg} / \mathrm{m}^{2}$ in the same manner, if their degree of adiposity is in the high range and/or if visceral adiposity is present. If such patients have medically pertinent disease related to their elevated adiposity, we recommend the diagnosis 'pre-obesity' in addition to the diagnosis of the respective disease. The diagnosis of pre-obesity will guide the physician with respect to monitoring and treatment of these individuals.

\section{Health Risks Associated with Obesity}

The BMI cutoff thresholds for adults were originally proposed in light of data indicating increased risks across the overweight range for associated medical disorders such as type 2 diabetes mellitus, cardiovascular disease, and different types of cancers [2]. The reported estimates for the population-attributable risks of obesity have been shown to range from 5 to $15 \%$ for all-cause mortality, from -0.2 to $8 \%$ for all-cancer incidence, from 7 to $44 \%$ for cardiovascular disease incidence, and from 3 to $83 \%$ for type II diabetes mellitus incidence [8].

In 2013, the American Medical Association declared obesity a disease [11]. Criticism of this far reaching step has centered on , e.g., the use of the BMI threshold of $30 \mathrm{~kg} / \mathrm{m}^{2}$ instead of an elevated waist-hip ratio to more precisely estimate associated medical risks and the fostering of a culture of individual irresponsibility; obesity can be viewed to merely represent a risk factor instead of a disease in itself [12]. Sims in 2001 [13] asked 'Are there persons who are obese, but medically healthy?' and thus initiated discussions centering on the term 'metabolically healthy obese'.

A recent large scale meta-analysis [14] based on a median follow-up of 13.7 years of almost 4 million people from Asia, Australia, New Zealand, Europe, and North America, who were never-smokers without chronic diseases at recruitment and who survived for 5 years, clearly revealed elevated sex-adjusted hazard ratios (HRs), relative to BMI $22.5-24.9 \mathrm{~kg} / \mathrm{m}^{2}$ throughout the overweight range (1.07 for BMI $25.0-27.49 \mathrm{~kg} / \mathrm{m}^{2} ; 1.20$ for BMI $27.5-29.9$ $\mathrm{kg} / \mathrm{m}^{2} ; 1.45,1.94$ and 2.76 for obesity class I, II and III). Mortality increased approximately log-linearly with BMI over $25.0 \mathrm{~kg} / \mathrm{m}^{2}$ in all continents; this increment was greater in younger than older people (1.52 for BMI measured at 35-49 years vs. 1.21 for BMI measured at 70-89 years) and greater in men than women (1.51 vs. 1.30). A BMI below $20 \mathrm{~kg} / \mathrm{m}^{2}$ was also associated with an elevated sex-adjusted HR.

The mortality risk attributable to obesity needs to be set into relationship to other risk factors. A recent multi-cohort study and meta-analysis with individual-level data from 48 independent prospective cohort studies revealed that low socioeconomic status was associated with a 2.1-year reduction in life expectancy between ages 40 and 85 years; the corresponding years-of-life-lost were 0.5 years for high alcohol intake, 0.7 years for obesity, 3.9 years for diabetes, 1.6 years for hypertension, 2.4 years for physical inactivity, and 4.8 years for current smoking [15]. 
Hebebrand et al.: A Proposal of the European Association for the Study of Obesity to Improve the ICD-11 Diagnostic Criteria for Obesity Based on the Three Dimensions Etiology, Degree of Adiposity and Health Risk

Irrespective of the elevated mortality, obesity is associated with a vast variety of somatic and to a lesser extent mental disorders, which do not necessarily entail elevated mortality, but clearly negatively impact growth, development, psychosocial adjustment, and/or health related quality of life. Indeed, it has been argued that the risks of obesity are much better explained as the risks of developing chronic conditions than by explaining mortality [16]. Obesity-related disorders represent a major burden for healthcare systems of many countries.

Substantial efforts have been made to better quantify the health risks associated with 'abnormal or excessive fat accumulation' upon use of additional anthropometric measures (e.g. waist and hip circumferences, skinfold thickness), sums or ratios thereof, determination of specific serum risk factors, and technological methods (e.g. bioelectrical impedance, dual energy X-ray absorptiometry, air displacement plethysmography, imaging techniques). Their delineation and clinical value assessment are clearly beyond the scope of this article. From a clinical perspective, such measures/methods should be inexpensive, easy to implement, allow monitoring of the disease, and be readily interpretable; the use of sex-specific age centiles for anthropometric measures is strongly recommended; these should be based on the respective national and/or ethnic population.

We recommend the use of age-, sex- and ethnicity-appropriate thresholds for the definition of elevated adiposity, the consideration of regional distribution of fat mass, and the delineation of the associated health risks. Such measures should indeed substantially improve risk stratification beyond the use of BMI per se. At the same time, we need to strive for simplicity: if the diagnostic assessment becomes too complex, too expensive and/or the benefits of these assessments are ambiguous, we should opt for simple solutions.

Sharma and coworkers $[17,18]$ introduced an obesity staging system based on the occurrence of risk factors, physical symptoms, psychopathology, functional limitations, and/or impairment of well-being related to obesity, importantly including obesity-related chronic disease and established end organ damage. Not surprisingly, this staging performed in US population-based individuals with a BMI $\geq 25 \mathrm{~kg} / \mathrm{m}^{2}$ was clearly superior to risk assessment via use of the BMI weight categories pre-obesity and obesity classes I-III.

We definitely need to improve the capability to predict risk and disease, particularly in the absence of obesity-related chronic disease and end organ damage. This would represent a tremendous step forward; we require research to come up with age-, sex- and ethnicitydependent algorithms, which should in light of their importance include information on family history data, particularly including the occurrence and age of onset of obesity- related chronic conditions in parents and siblings and, in case of their death, the length of life. The respective variables should represent independent risk factors of a predefined magnitude. Variables to be tested include sex, age, socioeconomic status and educational attainment, anthropometric measures, laboratory results, heart rate and blood pressure, habitual dietary intake and level of physical activity, tobacco use, and family history data. We envision that physicians will be able to fill in a data sheet online to come up with estimates for health risks particular to the respective patient. We are convinced that the underlying algorithms will enable a substantially improved risk prediction beyond BMI.

To conclude, an elevated BMI is associated with health risks including many diseases [19]. There is evidence to suggest that many of these health risks are at least in part causally related to an elevated level of adiposity, particularly if visceral adiposity is present. The health impact of obesity increases substantially across obesity classes I to III. A comparison with the risks imposed by other common and complex diseases is meaningful for guiding both treatment and prevention efforts. At the same time we note that obesity is a risk factor for several diseases that carry higher health risks than obesity itself. We see the research need for the development of readily applicable algorithms for the quantification of specific health 
Hebebrand et al.: A Proposal of the European Association for the Study of Obesity to Improve the ICD-11 Diagnostic Criteria for Obesity Based on the Three Dimensions Etiology, Degree of Adiposity and Health Risk

risks; BMI thresholds may prove helpful to determine what and the extent to which such risk factors require assessment. Physicians should be knowledgeable in these risk factors and diseases in order to accordingly guide the clinical assessment of a patient with obesity.

\section{Developmental Aspects}

The increments in prevalence rates for overweight and obesity have been particularly pronounced among children [4]. 42 million children under the age of 5 were overweight or obese around the globe in the year 2013 [9]. Because obesity can track into adolescence and adulthood, children and adolescents with overweight and obesity require particular medical attention. As a rule of thumb, obesity tracks into adulthood with a greater likelihood if i) the child is older (adolescents > children), ii) the higher the BMI is in comparison to children of the same age, and iii) if one or both parents are obese [20]. In young overweight/obese individuals some of the detrimental effects of an 'abnormal or elevated fat accumulation' may have a stronger impact over the lifespan than in adult onset obesity. Furthermore, obese adolescents are at a substantially elevated risk to develop class II and III obesity in adulthood, because the age-dependent increments in $\mathrm{kg} / \mathrm{m}^{2}$ are substantially higher in the upper as compared to the lower BMI centile range.

The WHO BMI-based weight categories for adults cannot be used for diagnosing obesity in children and adolescents. Instead, different cutoffs based on specific BMI age centiles as determined in reference populations have been used. In the US, overweight in children and adolescents is defined via the BMI age centile range between 85 and 95, obesity is defined as a BMI centile $\geq 95$ [21]. In Germany, BMI age centiles $\geq 90$ and $\geq 97$ are used to define overweight and obesity, respectively, in individuals aged $\leq 18$ years [22]. In other countries, different definitions of childhood overweight and obesity based upon national references, and adaptations of international references are also used. Due to the BMI increase over the past 40 years, the definition of childhood overweight and obesity via BMI age centile cutoffs based on older reference populations entails that the current rates are characteristically higher than the respective centile cutoffs would suggest. Cross-country comparisons are hampered by the differences in absolute values that constitute BMI age- and sex-specific centiles, especially in the upper range. To date, age- and sex-specific definitions by the WHO and the International Obesity Task Force are available for use in clinical practice; they also enable the study of cross-country comparisons and allow determination of secular increases in rates of childhood and adolescent overweight and obesity [23].

Because BMI continues to increase in adulthood, the age of an adult patient with obesity also requires reflection. According to a representative German population sample surveyed in $2005 / 2006,25.8 \%$ and $9.3 \%$ of the male as well as $20.7 \%$ and $7.2 \%$ of the female population aged 18-19 years are overweight (BMI $\geq 25 \mathrm{~kg} / \mathrm{m}^{2}$ ) and obese (BMI $\geq 30 \mathrm{~kg} / \mathrm{m}^{2}$ ), respectively [24]. In the eighth decade these numbers increase to lifetime maxima of $83.5 \%$ and $27.5 \%$ as well as $74.2 \%$ and $34.5 \%$, respectively (table 1 ). In adolescence and early adulthood, obesity is associated with more stigmatization with respect to social relationships and entry into the job market; a reduced self-esteem and other psychological problems as a consequence of excessive adiposity can ensue. Importantly, the obesity-related relative mortality risks decline with age [14]. Furthermore, according to the obesity paradox, patients with obesity have a greater chance of surviving specific diseases/disorders that typically occur in late adulthood. Finally, particularly sarcopenic obesity, characterized by an increased adiposity and a relatively reduced muscle mass, warrants medical attention in view of the related health risks in the elderly [25]. 
Hebebrand et al.: A Proposal of the European Association for the Study of Obesity to Improve the ICD-11 Diagnostic Criteria for Obesity Based on the Three Dimensions Etiology, Degree of Adiposity and Health Risk

Table 1. Relative frequency (\%) of the WHO weight categories underweight, normal weight, pre-obesity, and obesity [2] and number of subjects per age group (German National Nutrition Survey; ascertainment: 20052006) [24]

\begin{tabular}{|c|c|c|c|c|c|c|}
\hline \multirow[t]{2}{*}{ Sex } & \multirow{2}{*}{$\begin{array}{l}\text { Age, } \\
\text { years }\end{array}$} & \multicolumn{4}{|c|}{ BMI, $\mathrm{kg} / \mathrm{m}^{2}$} & \multirow[t]{2}{*}{$\mathrm{N}$} \\
\hline & & $<18.5$ & $18.5 \leq \mathrm{BMI}<25.0$ & $25.0 \leq \mathrm{BMI}<30.0$ & $\geq 30.0$ & \\
\hline \multirow[t]{8}{*}{ Females } & $18-19$ & 7.2 & 72.1 & 13.5 & 7.2 & 208 \\
\hline & $20-29$ & 5.5 & 68.2 & 17.7 & 8.6 & 746 \\
\hline & $30-39$ & 3.3 & 62.7 & 21.0 & 13.0 & 1,221 \\
\hline & $40-49$ & 1.0 & 52.8 & 28.7 & 17.5 & 1,626 \\
\hline & $50-59$ & 0.5 & 43.8 & 33.0 & 22.7 & 1,264 \\
\hline & $60-69$ & 0.6 & 32.1 & 37.8 & 29.5 & 1,312 \\
\hline & $70-79$ & 0.7 & 25.1 & 39.7 & 34.5 & 701 \\
\hline & total & 2.1 & 48.3 & 29.3 & 20.3 & 7,078 \\
\hline \multirow[t]{8}{*}{ Males } & $18-19$ & 5.5 & 68.8 & 16.5 & 9.3 & 237 \\
\hline & $20-29$ & 2.3 & 58.8 & 29.6 & 9.3 & 665 \\
\hline & $30-39$ & 0.6 & 42.1 & 43.9 & 13.3 & 938 \\
\hline & $40-49$ & 0.2 & 30.3 & 50.4 & 19.1 & 1,233 \\
\hline & $50-59$ & 0.2 & 23.8 & 48.8 & 27.2 & 1,098 \\
\hline & $60-69$ & 0.2 & 19.5 & 52.0 & 28.3 & 1,277 \\
\hline & $70-79$ & 0.2 & 16.3 & 56.0 & 27.5 & 661 \\
\hline & total & 0.7 & 31.7 & 46.5 & 21.1 & 6,109 \\
\hline
\end{tabular}

To sum up, obesity and its health risks cannot be judged adequately in both psychological and somatic terms without taking the age of a patient into account. Because in contrast to the WHO definitions of adult overweight (BMI $\geq 25 \mathrm{~kg} / \mathrm{m}^{2}$ ) and obesity (BMI $\geq 30 \mathrm{~kg} / \mathrm{m}^{2}$ ) overweight in children and adolescents is defined distinctly from obesity, we argue that a consistent definition be used. Depending on the wideness of the national BMI distribution, the respective BMI age centile cutoffs are $\geq 85$ th or 90 th and $\geq 95$ th or 97 th centiles for children or adolescents. In contrast to adults, we recommend that for children, and even more so for adolescents, overweight is also considered a disease if metabolic or cardiovascular risk factors can be detected.

\section{Sex Differences}

Both male and female sex hormones have well-known and profound influences on body fat distribution, ontogenetic pattern of fat accumulation, adipocyte function, development of the metabolic syndrome, and other health risks/diseases associated with obesity [26]. In brief, females are predisposed to stronger subcutaneous fat deposition resulting in the gynoid or gluteal-femoral pattern of adipose tissue distribution (pear shaped), males to visceral fat (apple shaped). Puberty, pregnancy, and menopause in females exert strong effects on regional fat deposition and accumulation; developmental and pregnancy-induced changes represent risk periods for an increase in adiposity. As a consequence of these sex differences, men have a higher risk of metabolic syndrome and cardiovascular disease; after menopause the respective risks increase in females. Genetic factors that sex specifically influence BMI and body fat distribution have been detected $[27,28]$.

Obesity in females of childbearing age warrants specific medical attention due to potential epigenetic and in utero effects in an embryo/fetus, which may increase the risk for obesity in 
Hebebrand et al.: A Proposal of the European Association for the Study of Obesity to Improve the ICD-11 Diagnostic Criteria for Obesity Based on the Three Dimensions Etiology, Degree of Adiposity and Health Risk

the offspring beyond the inherited polygenic risk. Obesity in pregnancy is associated with higher risk of miscarriage, congenital malformations, and birth complications including stillbirths. Due to intrauterine programming, elevated health risks for the offspring ensue. Obesity during pregnancy can also have short- and long-term adverse health consequences for the mother [29]. Both female [30] and male [31] fertility is reduced in obesity.

In conclusion, in addition to age, the sex of a patient with obesity is important with respect to the assessment of associated health risks. The implications of obesity in females of childbearing age for fertility, future pregnancy risks, and maternal and offspring outcomes need to be taken into account.

\section{Treatment: Relevant Aspects}

Substantial evidence has accumulated indicating that body weight in humans is regulated in a homeostatic manner. This regulation is of particular concern to patients with obesity. While individuals who wish to lose weight are frequently successful in doing so, the mediumand long-term success of maintaining the achieved body weight is poor. The mechanisms underlying the weight regain require further elucidation [32,33]. Upon weight loss complex homeostatic counterregulatory adaptations set in, which result in a resting metabolic rate well below that of BMI-matched controls. This reduced resting metabolic rate has recently been shown to persist even 6 years after weight loss [34]. For achievement of weight loss, a dietary intervention is more successful than an intervention aiming to increase the physical activity level; body weight management programs that combine diet and physical activity are seemingly more effective for weight loss over 12 months than interventions based on diet or physical activity alone [35].

The U.S. Prevention Services Task Force (USPSTF) concluded 'with moderate certainty that the net benefit of screening for obesity in children and adolescents age 6 years and older and offering or referring them to comprehensive, intensive behavioral interventions to promote improvements in weight status and certain cardiometabolic factors is moderate' (evidence grade B; draft recommendation statement) [36]. The USPSTF [37] had previously recommended screening all adults for obesity: Clinicians should offer or refer patients with a BMI of $30 \mathrm{~kg} / \mathrm{m}^{2}$ or higher to intensive, multicomponent behavioral interventions (also ranked as a grade B recommendation) [37]. In light of the small long-term effects of conventional weight loss programs, it has been argued that patients (and their caregivers) are informed accordingly prior to initiation of the program to allow for a decision based on realistic expectations [38]. Unlike other major causes of preventable death and disability, there are no exemplar national populations in which the obesity epidemic has been reversed by public health measures [39].

The medium- and long-term results of bariatric surgery in terms of weight loss and weight maintenance have been shown to far surpass those of conventional weight loss programs [40]. Bariatric surgery for obesity class III or obesity class II associated with obesityrelated comorbid disease also results in the improvement and remission of several comorbid conditions, and quality of life is improved [41]. Mortality rates have been shown to be lower after bariatric surgery in comparison to patients of the same BMI range, who did not forego surgery [42]. The WHO weight categorization [2] has been used to define eligibility for bariatric surgery, which commonly represents a treatment option for patients with a BMI $\geq$ $40 \mathrm{~kg} / \mathrm{m}^{2}$ (obesity class III) or a BMI $\geq 35 \mathrm{~kg} / \mathrm{m}^{2}$ with coexisting medical conditions. Nevertheless, we acknowledge that the access to bariatric surgery should not overly rely on specific BMI thresholds; it is the disease state of an individual patient that merits consideration. Indeed, recent clinical guidelines on obesity management do not consider BMI as a solo risk 
Hebebrand et al.: A Proposal of the European Association for the Study of Obesity to Improve the ICD-11 Diagnostic Criteria for Obesity Based on the Three Dimensions Etiology, Degree of Adiposity and Health Risk

factor or single indicator for the need to intervene [43]. The necessity for obesity management is defined by BMI, waist circumference, and comorbid disease(s).

A section on relevant treatment aspects is incomplete without reference to weight stigma [44], which is very frequent in diverse healthcare settings including physicians and even obesity specialists. In comparison to normal-weight patients, healthcare professionals spend less time in consultation with patients with obesity, thus entailing a reduced access to treatment. This may have a deleterious impact on patients with severe consequences: negative body image, poor self-esteem, avoidance of physical activity, increased risk of eating disorders, depression, and even suicidal ideations. Patients have the feeling of not being esteemed by their physician so that they may cancel their consultation and as a result receive less medical care, thus further increasing health risks. Children are particularly prone to weight stigmatization and teasing. Some success in decreasing stigmatization has been achieved [45] by appropriate education of healthcare professionals and medical students. The key message is that weight status and obesity are not under personal control. In the interaction with patients motivational interviewing has proven useful to avoid stigma. Motivational interviewing is a guided, patient-centered, non-judgmental and respectful counseling style. The medical equipment in the medical practice should be adapted to the needs of patients with obesity (e.g., appropriate blood pressure cuffs, scales, chairs without armrests); discrete weighing procedures should be offered in a private location.

\section{Complex Etiology}

Obesity results from a positive energy balance maintained over a prolonged period of time. The mechanisms underlying this positive energy balance are numerous, complex and to a large extent beyond willful control; they may only partially overlap between individual patients with obesity. As such, obesity is a multifactorial condition. Heritability of BMI is estimated at around 0.6 to 0.8 as based on twin studies and is similar across pre-adolescence into late adulthood [46]; unique environmental factors explain most of the environmental influence. The most recent meta-analysis of genome wide association studies identified 97 BMI loci which surpassed the criterion for genome wide significance [47]. Some of the respective alleles alter body weight by less than $200 \mathrm{~g}$. The respective alleles act in an additive manner to explain approximately $3 \%$ of the total BMI variation in a given population; nonadditive mechanisms have yet to be elucidated at the molecular level. We have just begun to investigate non-additive gene-gene or gene-environment interactions.

Single forms of monogenic obesity and syndromal obesity have been delineated. The respective elucidations have provided us with valuable insights into important central pathways for the regulation of body weight. In total, these forms of obesity account for 2-4\% of all individuals with obesity, amongst whom carriers of functionally relevant melanocortin-4 receptor gene mutations account for a large proportion. This autosomal dominant form of obesity has been shown to increase adult body weight by approximately 15 and 30 $\mathrm{kg}$ in males and females, respectively [48]. Autosomal recessively inherited leptin deficiency is the only form of monogenic obesity that can be treated causally via leptin replacement therapy [49].

Environmental factors (including our microbiome) play a crucial role for the development of obesity. However, within any given society the obesogenic environment may not differ that much entailing that genetic factors play a substantial role in explaining BMI variance of the respective population. It has proven difficult to dissect single environmental factors which beyond any doubt exert an influence on BMI. A sedentary lifestyle and overconsumption of foods are perceived as major players. Changes in the global food system, which is producing 
Table 2. Current classification of obesity according to the International Statistical Classification of Diseases and Related Health Problems 10th Revision (ICD-10) - WHO Version for 2016 [52]
Hebebrand et al.: A Proposal of the European Association for the Study of Obesity to Improve the ICD-11 Diagnostic Criteria for Obesity Based on the Three Dimensions Etiology, Degree of Adiposity and Health Risk

Endocrine, nutritional and metabolic diseases (E00-E90)

E65-68 Obesity and other hyperalimentation E66 Obesity

E66.0 Obesity due to excess calories

E66.1 Drug-induced obesity

E66.2 Extreme obesity with alveolar hypoventilation

E66.8 Other obesity (morbid obesity)

E66.9 Obesity, unspecified

palatable, more processed, cheap, and effectively marketed food, are thought to entail 'passive' overconsumption of energy. Overweight and obesity can thus be viewed as a predictable outcome of market economies predicated on consumption-based growth [39]. Social class is a predictor of body weight in industrial and developing countries - albeit with partially opposite effects [50,51].

Obesity can be potentially amenable to treatment if a major underlying cause can be identified. Thus, physicians need to be aware of specific diseases that may underlie excessive weight gain entailing obesity. A major depressive episode may entail weight gain, which can result in obesity; atypical depression is a subtype of depression which amongst other symptoms is frequently associated with weight gain. Immobilization can entail weight gain in thus predisposed individuals. Importantly, physicians should be alerted to the common occurrence of weight gain upon prescription of drugs that entail significant weight gain as a side effect, potentially leading to iatrogenic obesity . Obesity is also a well-established complication of hypothalamic surgery.

In conclusion, for the vast majority of individuals with obesity we cannot diagnose a major underlying cause. This type of obesity is best termed multifactorial; physicians need to understand that the predisposing genetic and environmental risk factors as well as their interactions only partially overlap between patients. We stress the importance to attempt identifying a major cause underlying the obesity of a patient because of potential therapeutic and prognostic implications. By doing so, we acknowledge the impossibility to indeed causally attribute the obesity of a patient to a major cause beyond any doubt in many cases; we provide guidelines for delineation of both the time frame and the weight increment to occur in obesity of a certain defined etiological factor; further research is required to validate the respective criteria. We have delineated single major factors, which must be viewed as provisional and are perceived as useful to guide future research; these factors are marked as such.

\section{A Look at the Current Classification Scheme ICD-10}

In ICD-10 [52], obesity was coded within the parent category 'Endocrine, nutritional and metabolic diseases' (E00-99; table 2). This parent term readily reflected the uncertainty pertaining to the classification of obesity, which was lumped together with endocrine, nutritional and metabolic diseases. Whereas endocrine, nutritional and metabolic factors obviously play a role in the development of obesity, other important factors such as energy expenditure or a sedentary or inactive lifestyle were not referenced. Due to inclusion of obesity within nutritional disorders, overt emphasis was placed on nutrition.

Obesity was subcategorized into 'Obesity due to excess calories' (E66.0), 'Drug-induced obesity' (E66.1), 'Extreme obesity with alveolar hypoventilation' (E66.2), 'Other obesity' (E66.8), and 'Obesity, unspecified' (E66.9) [52]. It is surprising that the subcategories were termed in this seemingly haphazard way, perhaps reflecting the former professional neglect 
Hebebrand et al.: A Proposal of the European Association for the Study of Obesity to Improve the ICD-11 Diagnostic Criteria for Obesity Based on the Three Dimensions Etiology, Degree of Adiposity and Health Risk

of obesity and the ignorance of its relevance. The subcategorization pertained to (assumed) causes, descriptive terms with a focus on comorbidity and the degree of obesity (morbid obesity was to be coded as 'Other obesity'). We are unable to diagnose 'Obesity due to excess calories', because we do not have a routine clinical method to determine the caloric intake of an individual. In addition, the sole reference to an excess caloric intake negates the complexity of the systems regulating both energy intake and expenditure; physical inactivity was not mentioned within the context of obesity. An excess energy intake relative to energy expenditure characterizes all types of obesity. The subcategories have made neither intuitive, logical nor professional sense and thus provided little guidance to the clinician.

\section{Critical Reflection on Overweight and Obesity within the Current ICD-11 Beta Draft}

Table 3 provides an overview of the classification and terminology used to describe overweight and obesity in the WHO ICD-11 Beta Draft [7]. Overweight and obesity are again categorized within 'Nutritional disorders', which as in ICD-10 belong to the parent 'Endocrine, nutritional and metabolic diseases'. As such, overweight and obesity continue to be conceptualized as nutritional disorders; this does not appear appropriate in light of the complexity of the mechanisms causally involved in development of an elevated BMI. The definition provided for the subcategory 'Overweight, obesity and specific nutrient excesses' is rudimentary and contrasts markedly with the detailed definitions given for e.g. specific genetic syndromes. The term 'body size is excessive' appears to stigmatize more than $50 \%$ of the population in many countries. Body composition or body fat distribution is not addressed, nor is any distinction made between fat-free and fat mass.

'Macro intake' is not a clearly defined biomedical term. It is unclear if this term refers to macronutrients. The meaning of an 'excess in energy and/or macro intake' is not readily comprehensible; the term by itself is not meaningful without referring to energy expenditure. Overweight and obesity are typically thought to ensue via an excess energy (or macronutrient) intake, if the total energy intake indeed exceeds energy expenditure over a prolonged period of time. The complex wiring of the neuroendocrine and physiological systems involved in body weight regulation has evolved to enable survival during famines; the systems are not geared to deal with the obesogenic environment of today. Including overweight/obesity within the category 'Nutritional disorders' does not reflect the potential contribution of a low energy expenditure due to a low resting metabolic rate and/or physical inactivity. Nutrients and in particular their intake merely represent one side of the energy balance relevant for the development of these weight categories.

The first category within the parent 'Overweight, obesity and specific nutrient excesses' is 'Overweight and obesity'. In contrast to other WHO definitions, the ICD-11 Beta-Draft [7] restricts the term overweight to the BMI range 25.0 to $29.9 \mathrm{~kg} / \mathrm{m}^{2}$; previously, this BMI range has been defined as pre-obesity and overweight was used to define the range $\geq 25 \mathrm{~kg} / \mathrm{m}^{2}$ and as such included obesity (see above). Because the scientific literature uses the term overweight for both pre-obesity and a BMI $\geq 25 \mathrm{~kg} / \mathrm{m}^{2}$, ICD 11 should take special care to clearly address this inconsistency and to provide a clear solution/definition; we favor adherence to the categorization proposed by the WHO in 2000 [2].

We pointed out the recent inclusion of obesity as a disease by the American Medical Association [11]. The ICD-11 Beta Draft [7] opens the door further by including overweight as a disease; however, pre-obesity more appropriately represents a risk factor for the development of obesity and/or of disorders associated with obesity. The medicalization of this common weight category overweight may decrease the motivation of healthcare profes- 
Hebebrand et al.: A Proposal of the European Association for the Study of Obesity to Improve the ICD-11 Diagnostic Criteria for Obesity Based on the Three Dimensions Etiology, Degree of Adiposity and Health Risk

Table 3. Classification of overweight and obesity in the ICD-11 Beta Draft [7]*

06 Endocrine, nutritional or metabolic diseases

Nutritional disorders

Overweight, obesity and specific nutrient excesses

Overweight and obesity

Overweight and localized adiposity

Overweight

Overweight in infants, children or adolescents

Risk of overweight in infants or children up to 5 years of age

Overweight in infants or children up to 5 years of age

Overweight in school-aged children or adolescents, 5 to 19 years

Overweight in adults

Localized adiposity

Fat pad

Benign symmetrical lipomatosis

Narrower Terms: Familial benign cervical lipomatosis

Obesity

Obesity due to energy imbalance

Obesity in children and adolescents

Obesity in infants or children up to 5 years of age

Obesity in school-aged children or adolescents from 5 to 19 years

Obesity in adults

Obesity with BMI 30.00-34.99

Obesity with BMI 35.00-39.99

Obesity with BMI greater than or equal to 40.00

Drug-induced obesity

Obesity hypoventilation syndrome

Leptin-related genetic obesity

Obesity due to congenital leptin deficiency

Obesity due to congenital leptin resistance

Obesity due to prohormone convertase- 1 deficiency

Obesity due to leptin receptor gene deficiency

Obesity due to pro-opiomelanocortin deficiency

Obesity due to melanocortin-4 receptor deficiency

Syndromes with obesity as a feature

Alström syndrome

Börjeson-Forssman-Lehmann syndrome

Cohen syndrome

MEHMO syndrome

Obesity due to 6q16 deletion

Prader-Willi syndrome

Sotos syndrome

Weaver syndrome

Wilson-Turner syndrome

Beckwith-Wiedemann syndrome

*For complete version see WHO, ICD-11 beta draft (accessed May 31, 2017) [7].

sionals to code overweight and to pay specific attention to the medical needs of patients with obesity. We propose to reserve the diagnosis of pre-obesity to individuals with an elevated adiposity, who have developed a metabolic and/or cardiovascular disease (see below); in children and adolescents the detection of any metabolic and/or cardiovascular risk factor related to an elevated adiposity merits the diagnosis of pre-obesity.

The problem inherent to the inclusion of overweight in the Beta Draft is compounded by the subcategory 'Risk of overweight in infants or children up to five years of age', which 
Hebebrand et al.: A Proposal of the European Association for the Study of Obesity to Improve the ICD-11 Diagnostic Criteria for Obesity Based on the Three Dimensions Etiology, Degree of Adiposity and Health Risk

clearly lists a risk factor, and not a disease. Using this definition, slightly more than $13 \%$ of all infants and young children would fulfill the given centile range from 84.1 to 97.7; a substantially higher number is at 'risk of overweight' if an older reference sample is used. Use of a centile cutoff value with a decimal is not helpful for clinicians; the complex information given to correctly assess length/height is not readily transferable to routine clinical assessments.

The subcategory 'Overweight and localized adiposity' and its two sub-definitions appear problematic because the term localized adiposity is not a common clinical diagnosis; the term should not be used in the classification scheme due to difficulties in clearly defining such a regional adipose tissue mass. If 'fat pad' and 'benign symmetrical lipomatosis' warrant diagnostic representation, they should not be listed together with overweight.

The centiles provided in the ICD-11 Beta Draft for a definition of 'Risk of overweight in infants or children up to five years of age', 'Overweight in infants or children up to five years of age', and 'Overweight in school-aged children or adolescents, 5 to 19 years' change. Whereas the first and third subcategory are based on the same centile cutoffs, 'Overweight in infants or children up to five years of age' entails a more severe degree of adiposity. The complexity of this classification of infant, childhood and adolescent obesity will likely not take off among pediatricians and general practitioners - it is just too impractical; furthermore, as a child transverses the age range from month 60 to 61, a different centile cutoff applies. Only the definition of a narrowly defined obesity appears meaningful in infants and children up to age 5. At this developmental stage excess adiposity does not entail substantially elevated risks for the development of late childhood, adolescent or adult obesity; even 'obesity' in infancy or early childhood does not track well into later life, unless one or both parents are obese [53].

Obesity is subdivided into 'Obesity due to energy imbalance', 'Drug-induced obesity', 'Obesity hypoventilaton syndrome', 'Leptin-related genetic obesity', and 'Syndromes with obesity as a feature'. All five appear to relate to different mechanisms underlying the development of obesity. However, an 'energy imbalance' also underlies the development of 'Druginduced obesity', 'Leptin-related genetic obesity', and the 'Obesity hypoventilation syndrome', which does not represent a well-defined medical entity; the definition given in the ICD-11 Beta Draft version may warrant an alternative inclusion among disorders of the lung and in particular alveolar hypoventilation. Undoubtedly, drug-induced weight gain can represent a serious problem for individuals who require medication with this side effect. Nevertheless, caution is warranted because a drug-induced weight gain of $15 \mathrm{~kg}$ in a lean patient with underweight at baseline may represent a much more serious problem than a 1-kg weight gain in an individual who had a BMI marginally below $30 \mathrm{~kg} / \mathrm{m}^{2}$ upon initiation of the medication. Overall, it appears somewhat problematic to classify side effects of medications within ICD-11, the major question being where to draw a line - what medication side effects warrant their listing as a disease entity? The inclusion of 'Leptin-related genetic obesity' appears problematic because confirmation by genetic testing is required; just recently, mutations in the leptin gene were detected that do not entail leptin deficiency [54], implying that in theory the leptin gene would have to be screened for functionally relevant mutations in all patients with extreme obesity, which is not readily feasible. Furthermore, the text lists mutations in the peroxisome proliferator-activated receptor gamma gene which are not directly related to leptin. Physicians should not find disorders in a clinical classification scheme that have only rarely been reported; according to the Beta Draft 'Obesity due to prohormone convertase-I deficiency' has only been described in two patients (this statement is incorrect). Instead, an overall classification scheme should take single entities with a major single genetic cause of obesity into account.

A BMI for age above three standard deviations of the median (z-score $\geq 3$ ) is used to diagnose 'Obesity in infants or children up to five years of age'; in the older group two standard deviations represent the cutoff. Pointing out the equivalent of this cutoff at age 19 to a BMI of 
Table 4. Proposal for the structure of the classification of obesity in ICD-11

06 Endocrine, nutritional and metabolic diseases

07 Obesity

Dimension 1: Etiology

Obesity, multifactorial

Obesity attributable to a certain defined etiological factor

Obesity, iatrogenic

Obesity arising from or aggravated by drug induced weight gain

Obesity arising from or aggravated by other iatrogenic procedures

Obesity arising from or aggravated by a certain defined disease/condition

Obesity arising from or aggravated by a certain defined endocrine disease

Obesity arising from or aggravated by a certain defined neoplasm

Obesity arising from or aggravated by major depressive disorder

Obesity arising from or aggravated by immobilization/inactivity

Obesity attributable to more than one certain defined etiological factor

Obesity due to monogenic disease / genetic syndrome

Obesity due to other major causes

Dimension 2: Degree of adiposity

Obesity class I

Obesity class II

Obesity class III

Obesity class IV

Obesity class V

Obesity class VI

Dimension 3: Health risk

Low

Intermediate

High

$30 \mathrm{~kg} / \mathrm{m}^{2}$ needs to be reflected upon critically because at this age and during young adulthood the prevalence of obesity is substantially lower than in older adults. However, young adults with a BMI of 28 or $29 \mathrm{~kg} / \mathrm{m}^{2}$ already have a substantial risk for obesity-related comorbidities. In addition, they are at an elevated risk to develop class II and III obesity.

\section{EASO Proposal for the ICD-11 Classification of Obesity}

In tables 4 and 5 , we propose a classification of obesity that is more consistent with current terminology and definitions. The classification enables the clinician to logically, professionally and intuitively grasp the subdivisions. We propose a separate overarching parent termed 'Obesity' to indicate that obesity should not be listed with endocrine and metabolic diseases; obesity is too common and too complex to remain within this category, in particular because the causal link to endocrine and metabolic disease may be weak in many patients (i.e., inactivity). Obesity should not constitute a subcategory of nutritional disorders (see above). Children, adolescents and adults are dealt with within each diagnostic category within the parent 'Obesity'.

The diagnosis of obesity rests on a BMI $\geq 30 \mathrm{~kg} / \mathrm{m}^{2}$ (in non-Caucasian populations other cutoffs are appropriate to define similar health risks); however, the physician must ensure that an elevated adiposity constitutes a substantial proportion of the body weight of the respective patient. Thus, whereas the BMI cutoff $\geq 30 \mathrm{~kg} / \mathrm{m}^{2}$ serves as a useful operational 
Hebebrand et al.: A Proposal of the European Association for the Study of Obesity to Improve the ICD-11 Diagnostic Criteria for Obesity Based on the Three Dimensions Etiology, Degree of Adiposity and Health Risk

Table 5. Proposal for the classification of obesity in ICD-11

07 Obesity

Dimension 1: Etiology

Obesity, multifactorial

This category is to be used for patients with obesity, for which no certain defined etiological factor can be identified. For these patients obesity is the result of complex interactions of a large number of genetic and environmental factors, some of which can be identified (e.g. predisposing genetic variants with small effect sizes). Obesity, multifactorial applies to the majority of patients with obesity. Weight gain can be pronounced during specific time periods (e.g. puberty, postpregnancy, or menopause). In medical terms, obesity is important because it is associated with a large number of somatic (including e.g. type 2 diabetes mellitus, cardiovascular disease, metabolic syndrome, diverse types of cancer, musculoskeletal disease) and to a lesser extent mental diseases (e.g. major depressive disorder), which if applicable should be coded separately; in general, risks for these associated diseases increase with increasing BMI. It is noteworthy to point out that a considerable number of the individuals with obesity are metabolically healthy; however, due to the increased health risks of such individuals a heightened medical surveillance is advised. This applies all the more so for younger individuals. Health care professionals need to be aware of the complexity of body weight regulation; importantly, after intentional weight loss a complex counter-regulation sets in, that results in an energy expenditure well below that of other BMI matched controls for extended periods of time. Accordingly, most patients with obesity have substantial difficulties with weight maintenance after achievement of conservative weight loss.

Definition: Obesity in adults is most frequently defined via a BMI $\geq 30 \mathrm{~kg} / \mathrm{m}^{2}$ in many Caucasian populations; in some non-Caucasian (e.g. Asian) populations a lower threshold is applicable. An elevated adiposity is understood as an elevated fat mass as a prerequisite for the diagnosis of obesity. The use of additional anthropometric measures and/or techniques is strongly recommended to substantiate the elevated adiposity; age, sex and ethnicity need to be taken into account to interpret the respective measures/results. Particularly, visceral fat accumulation entails elevated risks for the development of several obesity associated diseases, which include metabolic diseases and type 2 diabetes mellitus in particular, cardiovascular disease and various types of cancers. The measurement of waist circumference as a surrogate marker of visceral fat is strongly recommended to estimate the risk for the development of such diseases; in addition the medical assessment of such a patient should include measurement of blood pressure and determination of blood glucose and lipids; in males and females of European origin the risk for metabolic disorders is increased or substantially increased if weight circumference equals or exceeds 94 and $102 \mathrm{~cm}$, and 80 and $88 \mathrm{~cm}$, respectively (WHO, 2000); other cutoffs are applicable to patients of other ethnicities. Globally, rates of obesity have increased over the last decades and in multiple countries obesity now occurs in more than $20 \%$ of the adult population. The proportion of the adult population with a $\mathrm{BMI} \geq 30 \mathrm{~kg} / \mathrm{m}^{2}$ is typically rather low in young adulthood and substantially higher in later decades of life. As a rule of thumb, a BMI of $30 \mathrm{~kg} / \mathrm{m}^{2}$ in an 18-year-old is of substantially greater medical concern with respect to the medium and longer term development of medical sequelae than the same BMI in a 50 or 60 year old patient.

For children and adolescents BMI age centiles for both boys and girls are available in many countries. The 95th or 97th BMI age centiles (approximately equivalent to +2 standard deviations; for simplicity we subsequently refer to the 95 th) are often used as thresholds for the diagnosis of obesity in children and adolescents. Absolute BMI values, that constitute a particular BMI centile in the upper range, can vary considerably between countries, thus rendering cross-country centile based comparisons difficult. Because the mean BMI of children and adolescents has increased also over the past decades, care must be applied upon the use of recent population based samples to avoid an underestimation of obesity prevalence rates. Adolescent BMI tracks into adulthood; in contrast, the BMI in infancy tracks little into adolescence and adulthood. In general terms, the likelihood that an age adjusted elevated BMI of individuals aged less than 18 years predicts adult obesity, is higher the older the individual and the higher the age adjusted BMI at baseline. The risk is further increased if one or both parents are obese. In principle, the medical risks associated with obesity apply to children and adolescents as well; for several obesity-related diseases they are increased in comparison to those observed in adults. Children, adolescents and young adults with obesity are particularly prone to weight related teasing and other types of stigmatization.

Binge eating can be associated with Obesity, multifactorial. If the criteria for Binge Eating Disorder are met, this disorder is to be coded additionally. 
Table 5. Continued

\section{Obesity}

Obesity attributable to a certain defined etiological factor

It is important to recognize an underlying certain defined etiological factor in the development of obesity, because such a factor may require a specific medical approach. This diagnostic category should be used only if the specific etiological factor can be established without reasonable doubt. Quantitative criteria to establish a clinically relevant weight gain are provided where appropriate.

Obesity, iatrogenic

Obesity arising from or aggravated by drug induced weight gain

The diagnosis of Obesity arising from or aggravated by drug induced weight gain requires 1) a BMI $\geq 30 \mathrm{~kg} / \mathrm{m}^{2} \mathrm{in}$ adults or $\geq 95$ th centile in children and adolescents and elevated adiposity, 2) a noticeable and clinically relevant drug induced weight gain exceeding $5 \%$ of body weight at baseline within a 4-month period upon initiation of the drug treatment beyond any reasonable doubt, 3) the respective drug (or a set of different drugs) is known to induce weight gain as a side effect, 4) the weight gain cannot be attributed to another etiological factor.

Because several medications - common examples include insulin (treatment of both type 1 and 2 diabetes mellitus), glucocorticoids and some anticonvulsants and psychotropic drugs (specific antipsychotics, antidepressants, antianxiety agents, and mood stabilizers) - can induce weight gain in predisposed individuals, drug-induced obesity represents a comparatively common major cause of obesity. Drug induced weight gain may negatively affect adherence to the respective medication (scheme). A careful assessment of current and previous medication use is warranted in individuals with obesity. If feasible, medication should be switched to a substance that does not induce this side effect. Weekly weight monitoring is important for individuals who are newly prescribed medications that are known to frequently induce weight gain.

Patients with Obesity arising from or aggravated by drug induced weight gain will as a rule have one or more additional disorders that led to the respective drug treatment; this disorder(s) should be coded accordingly.

Obesity arising from or aggravated by other iatrogenic procedures

The diagnosis of Obesity arising from or aggravated by other iatrogenic procedures requires 1) a BMI $\geq 30 \mathrm{~kg} / \mathrm{m}^{2}$ in adults or $\geq 95$ th centile in children and adolescents and elevated adiposity, 2) a noticeable and clinically relevant drug induced weight gain exceeding $5 \%$ of body weight at baseline within a 3-month period induced by an iatrogenic procedure other than the prescription of a drug, 3) the respective procedure is known to induce weight gain as a side effect, 4) the weight gain cannot be attributed to another etiological factor.

Relevant examples include neurosurgical procedures involving the hypothalamus (e.g. due to resection of a craniopharyngioma) and radiation therapy for brain tumors. Obesity due to other iatrogenic factors explains only a very small proportion of obesity in the general population. Nevertheless, the causal link to the respective procedure and the association with the underlying condition warrant this distinct diagnostic category.

Patients with Obesity arising from or aggravated by other iatrogenic procedures will as a rule have a disorder that led the physician to use the respective procedure; this disorder should be coded accordingly.

Obesity arising from or aggravated by a certain defined disease/condition

This category is reserved for patients with defined diseases, in whom noticeable and clinically relevant weight gain results in obesity or aggravates existent obesity. The respective disease/condition is known to directly or indirectly underlie the weight gain.

Table 5 continued on next page

definition for obesity, we agree that it should not be used as the conceptual definition [55]. Further research is required to improve the operational definition of obesity. The diagnosis of obesity is warranted, irrespective of whether obesity-related diseases are present or not. The physician must use additional anthropometric measures or technical procedures to substantiate the elevated adiposity; the use of sex-and age-specific centiles is strongly recommended, which should if possible be based on the respective ethnic population. We acknowledge that we currently do not have a 'one size fits all' definition for elevated adiposity, particularly because the regional fat distribution is very important for delineation of the health risks associated with obesity. 
Hebebrand et al.: A Proposal of the European Association for the Study of Obesity to Improve the ICD-11 Diagnostic Criteria for Obesity Based on the Three Dimensions Etiology, Degree of Adiposity and Health Risk

Table 5. Continued

Obesity arising from or aggravated by a certain defined endocrine disease

The diagnosis of Obesity arising from or aggravated by a certain defined endocrine disease requires 1 ) a BMI $\geq$ $30 \mathrm{~kg} / \mathrm{m}^{2}$ in adults or $\geq 95$ th centile in children and adolescents and elevated adiposity, 2) a noticeable and clinically relevant weight gain exceeding $10 \%$ of premorbid body weight induced by a certain defined endocrine disease, 3 ) the respective endocrine disease is known to induce weight gain, 4) the weight gain cannot be attributed to another etiological factor.

Endocrine disease entailing significant weight gain is frequently associated with other symptoms potentially also including a reduced growth in height, the combination of which may pave the way to the respective diagnosis. Relevant examples include Cushing's disease, growth hormone deficiency and hypothyroidism. The respective disorder should be coded separately.

Obesity arising from or aggravated by a certain defined endocrine disease explains only a small proportion of obesity in the general population. Nevertheless, the associated clinical symptoms and the potential treatment of the endocrine disease warrant this distinct diagnostic category.

The underlying endocrine disease requires a separate coding.

An endocrine active neoplasm (e.g. pituitary adrenocorticotropin hormone (ACTH)) and paraneoplastic syndromes, which have induced noticeable weight gain, should be coded as both Obesity arising from or aggravated by a certain defined endocrine disease and Obesity arising from or aggravated by a certain defined neoplasm. Similarly, monogenic disorders/genetic syndromes, which result in an endocrine disease that causally induces weight gain (e.g. leptin deficiency or leptin receptor mutations), should be classified here; in addition, in these rare cases Obesity due to a monogenic disorder/genetic syndrome should also be coded.

Obesity arising from or aggravated by a certain defined neoplasm

The diagnosis of Obesity arising from or aggravated by a certain defined neoplasm requires 1) a BMI $\geq 30 \mathrm{~kg} /$ $\mathrm{m}^{2}$ in adults or $\geq 95$ th centile in children and adolescents and elevated adiposity, 2) a noticeable and clinically relevant weight gain exceeding $10 \%$ of premorbid body weight induced by a certain defined neoplasm, 3) the respective neoplasm is known to induce weight gain, 4) the weight gain cannot be attributed to another etiological factor. Craniopharyngeomas and tumors of the hypothalamus represent an example for this diagnostic category.

Obesity arising from or aggravated by a certain defined neoplasm explains only a small proportion of obesity in the general population. Nevertheless, the associated clinical symptoms and the potential treatment of the neoplasm warrant this distinct diagnostic category.

Rarely, a tumor can have a significant tumor mass, which can lead to the diagnosis of Obesity arising from or aggravated by a certain defined neoplasm. A hypothalamic tumor that promotes overeating should also be classified here. Finally, this diagnosis is warranted in addition to that of Obesity arising from or aggravated by a certain defined endocrine disease if the neoplasm directly or indirectly induces weight gain via an endocrine mechanism. If the endocrine active neoplasm is the result of a monogenic disorder (e.g. multiple endocrine neoplasm I and II), a third diagnosis of Obesity due to monogenic disorders/genetic syndromes is warranted. The underlying neoplasm requires a separate coding.

Table 5 continued on next page

Reference to overweight was omitted as this weight category is based on a BMI $\geq 25$ $\mathrm{kg} / \mathrm{m}^{2}$ and thus includes the BMI range for obesity (WHO [2]). We reserve the diagnosis 'Preobesity' $\left(25.0<\mathrm{BMI}<30 \mathrm{~kg} / \mathrm{m}^{2}\right.$ in Caucasian populations) for those adult patients who additionally have a metabolic and/or cardiovascular disease related to an elevated adiposity, acknowledging that the link to elevated adiposity does not necessarily imply causality (e.g., physical inactivity or other lifestyle-related factors may represent the major or part of the causal link in a subgroup). The link to only metabolic and cardiovascular diseases pays reference to those diseases, whose occurrence risks attributable to elevated adiposity are 
Hebebrand et al.: A Proposal of the European Association for the Study of Obesity to Improve the ICD-11 Diagnostic Criteria for Obesity Based on the Three Dimensions Etiology, Degree of Adiposity and Health Risk

Table 5. Continued

Obesity arising from or aggravated by major depressive disorder

The diagnosis of Obesity arising from or aggravated by major depressive disorder requires 1) a BMI $\geq 30 \mathrm{~kg} / \mathrm{m}^{2}$ in adults or $\geq 95$ th centile in children and adolescents and elevated adiposity, 2) a noticeable and clinically relevant weight gain exceeding $10 \%$ of body weight within 6 months of one or more major depressive episodes, 3) the weight gain cannot be attributed to another etiological factor; in particular, a diagnosis of Obesity arising from or aggravated by drug induced weight gain needs to be excluded. An increased appetite and/or weight gain and/or a decreased activity level represent symptoms of a major depressive episode. As such, a subgroup of patients with major depressive disorder develops obesity; atypical depression is a frequently used diagnostic label for this subgroup.

The mood disorder is to be coded separately. It should be pointed out that there is no solid evidence for the requirement of a weight gain of at least $10 \%$ within one or more major depressive episodes within a six month period for the diagnosis of Obesity arising from or aggravated by major depressive disorder. For this reason, no precise estimate is available for the frequency of this disorder; in addition, the course of Obesity arising from or aggravated by major depressive disorder warrants research. The reason for inclusion of Obesity arising from or aggravated by major depressive disorder in ICD-11 is the sizeable proportion of patients with obesity who report a strong association of their disorder with an episode of major depression; furthermore, this subgroup may have other metabolic risk factors.

Obesity arising from or aggravated by immobilization/inactivity

The diagnosis of Obesity arising from or aggravated by immobilization/inactivity requires 1) a BMI $\geq 30 \mathrm{~kg} / \mathrm{m}^{2}$ in adults or $\geq 95$ th centile in children and adolescents and elevated adiposity, 2) a noticeable and clinically relevant weight gain exceeding $10 \%$ of body weight within 6 months, 3) the weight gain cannot be attributed to another etiological factor. Patients of all ages with Obesity arising from or aggravated by immobilization/ inactivity initially suffer an injury or a disease, which within a short period of time leads to a state of relative immobilization. Patients are thus not able to continue their physically active lifestyle. Whereas fat free mass is lost, fat mass increases. In older individuals, Obesity arising from or aggravated by immobilization/inactivity also includes individuals who have become physically inactive without a defined cause; as such this category overlaps with sarcopenic obesity.

The result of the injury (e.g. bone fracture) or the disease should be coded separately. It should be pointed out that there is no scientific evidence for the arbitrary requirement of a weight gain of at least $10 \%$ within a 6-month period for the diagnosis of Obesity arising from or aggravated by immobilization/inactivity. For this reason, no precise estimate is available for the frequency of this disorder; in addition, the course of Obesity arising from or aggravated by immobilization/inactivity warrants research. The reason for inclusion of Obesity arising from or aggravated by immobilization/inactivity in ICD-11 is the sizeable proportion of patients with obesity who report a strong association of their immobilization/inactivity with a noticeable and clinically relevant weight gain. In addition, in older individuals the overlap with sarcopenic obesity is clinically useful to acknowledge the particular health risks inherent to loss of fat free mass in combination with an increase in fat mass.

Table 5 continued on next page

high. Because the increase in all-cause mortality is rather low for the BMI range 25-29.9 $\mathrm{kg} / \mathrm{m}^{2}$ in comparison to the BMI range $20-24.9 \mathrm{~kg} / \mathrm{m}^{2}$, we do not diagnose 'Pre-obesity' in the absence of metabolic and/or cardiovascular diseases. However, physicians must recognize this BMI range as a risk factor for the development of obesity and related disorders, particularly in younger adult patients.

In children and adolescents, 'Pre-obesity' (BMI centile between 85 and 95 or 90 and 97 in Caucasian populations) is to be additionally diagnosed in patients with any type of metabolic and/or cardiovascular risk factor associated with an elevated adiposity. 
Hebebrand et al.: A Proposal of the European Association for the Study of Obesity to Improve the ICD-11 Diagnostic Criteria for Obesity Based on the Three Dimensions Etiology, Degree of Adiposity and Health Risk

Table 5. Continued

07 Obesity

Obesity attributable to more than one certain defined etiological factor

The diagnosis of Obesity attributable to more than one certain defined etiological factor requires 1) a BMI $\geq 30 \mathrm{~kg} /$

$\mathrm{m}^{2}$ in adults or $\geq 95$ th centile in children and adolescents and elevated adiposity as a result of a noticeable and clinically relevant weight gain which may be attributable to any combination of the diseases/conditions listed under the parent Obesity attributable to a certain defined factor. In light of the applicability of more than one factor the clinician is not able to unequivocally delineate a single factor underlying the weight gain. Examples include a noticeable and clinically relevant weight gain in 1) patients with major depressive disorder, who are concomitantly treated with a drug known to induce weight gain, 2) patients who experienced an immobilization and suffer from major depressive disorder.

Obesity due to monogenic disease/genetic syndrome

The diagnosis of Obesity due to monogenic disease/genetic syndrome requires 1) a BMI $\geq 30 \mathrm{~kg} / \mathrm{m}^{2}$ in adults or $\geq 95$ th centile in children and adolescents and elevated adiposity as a result of a noticeable and clinically relevant weight gain that is related to the respective monogenic disorder/genetic syndrome, 2) the respective monogenic disease/genetic syndrome is known to causally underlie the development of obesity or to show a strong association with obesity, 3) the weight gain cannot be attributed to another etiological factor.

Obesity due to monogenic disease/genetic syndrome explains only a small fraction of patients with obesity. Dysmorphic features and/or other somatic symptoms (e.g. infertility) and/or a reduced cognitive functioning in combination with obesity may give rise to the suspicion of an underlying syndrome. These diseases may be due to chromosomal aberrations (e.g. Down syndrome), contiguous gene syndromes (e.g. Prader-Willi syndrome) or monogenic diseases (e.g. functionally relevant mutations in the leptin or melanocortin-4 receptor genes). Some of the respective diseases/syndromes are exceedingly rare and have in some cases (e.g. leptin deficiency due to functionally relevant mutations in the leptin or leptin receptor genes) been detected worldwide in a few families only. In contrast, functionally relevant mutations in the $M C 4 R$ have been identified in one to five percent of individuals with (extreme) obesity. All other distinct forms of obesity due to chromosomal aberrations, contiguous gene syndromes or monogenic diseases are infrequent to rare.

Pre-obesity of any etiology

The diagnosis of Pre-obesity is based on 1) the occurrence of disease strongly related to adiposity, 2) an elevated degree of adiposity and/or visceral adiposity, and 3) a BMI in the range of 25.0 to $29.9 \mathrm{~kg} / \mathrm{m}^{2}$; if clearly warranted the diagnosis may be extended to patients with a BMI $<25 \mathrm{~kg} / \mathrm{m}^{2}$. Relevant diseases include hypertension, dyslipidemia, metabolic syndrome, nonalcoholic fatty liver disease (NAFLD), type 2 diabetes mellitus, myocardial infarction and stroke. Both the degree of adiposity and the regional fat distribution need to be assessed using appropriate measures/techniques. The clinician should make use of the etiological subcategorizations of obesity to potentially identify a certain defined etiological factor. The disease strongly related to adiposity requires separate coding.

In children and adolescents, Pre-obesity (BMI centile between 85 and 95 or 90 and 97 in Caucasian populations) is to be additionally diagnosed in patients with any type of metabolic and/or cardiovascular risk factor associated with an elevated adiposity.

Table 5 continued on next page

The proposed classification is based on our current knowledge as to specific mechanisms underlying the development of obesity, which currently have been elucidated to a small extent only. The classification centers on three dimensions: 1) etiology, 2) degree of adiposity, and 3) health risk.

1 Etiology: Patients with obesity not due to a known certain defined etiological factor are to be diagnosed with 'Obesity, multifactorial'; the respective definition pays reference to the complexity of this disease, which arises from environmental and genetic risk factors in addition to gene-gene, gene-environment and genome-environment interactions. 
Table 5. Continued

07 Obesity

Dimension 2: Degree of adiposity

Obesity in adults is subdivided into six different classes (I-VI; see below); this sub-classification is useful for defining subgroups eligible for particular treatments (e.g. bariatric surgery). The staging recognizes the fact that rates of extreme obesity have increased substantially in many countries over the last decades.

Obesity class I

The adult BMI is in the range of 30.0 to $34.9 \mathrm{~kg} / \mathrm{m}^{2}$. Medical risks associated with obesity are slightly elevated in comparison to individuals with a normal weight.

In children and adolescents the BMI is in between the +2 and +3 standard deviation of an appropriate reference population.

Obesity class II

The adult BMI is in the range of 35.0 to $39.9 \mathrm{~kg} / \mathrm{m}^{2}$. Medical risks associated with obesity are elevated in comparison to individuals with a normal weight.

In children and adolescents the BMI is in between the +3 and +4 standard deviation of an appropriate reference population.

Obesity class III

The adult BMI is in the range of 40.0 to $44.9 \mathrm{~kg} / \mathrm{m}^{2}$. Medical risks associated with obesity are substantially elevated in comparison to individuals with a normal weight.

In children and adolescents the BMI is in between the +4 and +5 standard deviation of an appropriate reference population.

Obesity class IV

The adult BMI is in the range of 45.0 to $49.9 \mathrm{~kg} / \mathrm{m}^{2}$. Medical risks associated with obesity are substantially elevated in comparison to individuals with a normal weight.

In children and adolescents the BMI is in between the +5 and +6 standard deviation of an appropriate reference population.

Obesity class $\mathrm{V}$

The adult BMI is in the range of 50.0 to $54.9 \mathrm{~kg} / \mathrm{m}^{2}$. Medical risks associated with obesity are substantially elevated in comparison to individuals with a normal weight.

In children and adolescents the BMI is in between the +6 and +7 standard deviation of an appropriate reference population.

Obesity class VI

The adult BMI exceeds $55.0 \mathrm{~kg} / \mathrm{m}^{2}$. Medical risks associated with obesity are substantially elevated in comparison to individuals with a normal weight.

In children and adolescents the BMI equals or is above the seventh standard deviation of an appropriate reference population.

Table 5 continued on next page

'Obesity attributable to a certain defined etiological factor' is overall less frequent than 'Obesity, multifactorial'; for all categories within 'Obesity attributable to a certain defined etiological factor', we posit that the respective patients must have a BMI equal to or above the age appropriate cutoff and an elevated adiposity; in addition, the weight gain entailing a BMI at or above the respective age-appropriate threshold must be noticeable and clinically relevant. Importantly, within 'Obesity attributable to a certain defined etiological factor' we refer to 'Obesity, iatrogenic' to alert a physician as to the possibility that obesity can arise as a consequence of the intake of specific drugs or other medical procedures. Because of the comparably common side effect of weight gain for different medications and the amenability to potential treatment via discontinuation of the respective drug, we maintain reference to 'Obesity arising from or aggravated by drug induced weight gain', despite the fact that drug side effects cannot readily be considered as diseases. 
Table 5. Continued

\section{Obesity}

Dimension 3: Health risk

A staging according to health risk is of crucial importance to assess the health implications of obesity with respect to age, sex, ethnicity, and family history. Such a staging needs to take current knowledge of obesity/adiposity related health risks into account. The proposed staging system requires systematic validation in prospective population based studies; as such the staging system must be considered as preliminary.

Low

The absence of risks and obesity/adiposity related diseases delineated in the intermediate and high health risk stages Intermediate

1) positive family history for adiposity related disease (primarily type 2 diabetes mellitus, hypertension, myocardial infarction, stroke) in first degree relatives, 2) Obesity class $\geq 1$ in patients aged $\leq 30$ and obesity class $\geq 2$ in patients aged $\geq 30,3$ ) visceral obesity, 4) evidence of impaired glucose tolerance, 5) hypertension, 6) hypercholesterolemia and/or hypertriglyceridemia, 7) regular tobacco use, 8) physical inactivity. High

1) type 2 diabetes mellitus, 2) metabolic syndrome, 3) cardiovascular/renal end organ damage, 4) obesity related musculoskeletal disorders that significantly impinge health

2 Degree of Adiposity: The BMI threshold for adult obesity is $30 \mathrm{~kg} / \mathrm{m}^{2}$; obesity in children is generally diagnosed if the BMI equals or is in excess of the age- and sex-specific 95th or 97 th centile. Cutoffs may vary by country, however, and different values may apply to non-Caucasian populations. The dimensional categorization of different classes of obesity extends the WHO categorization to a total of six classes. We deem this extension relevant because of the secular increase of extreme degrees of obesity and to allow a better staging of patients with such an extreme degree of adiposity. For children and adolescents, our classification scheme is based on multiples of the standard deviation score (SDS- or z-scores).

3 Health Risk: Because of the difficulties inherent to the assessment of health risks via BMI alone, the health risk of an obese patient requires further specification. While we realize that such an assessment is highly complex and dependent on age, sex and ethnicity among other variables, we nevertheless deem it necessary to provide the physician with a general rule of thumb as to how to assess the health risk of an individual obese patient. Research is warranted to better quantify the interactions of the different factors used to assess health risk; furthermore, physicians should be provided with tools (e.g. , algorithms, software programs) to more reliably and validly assess the health risk.

\section{Conclusion}

Obesity is a complex disease, which in the majority of patients has a multifactorial basis; obesity can be (largely) attributable to a certain defined etiological factor in a minority of patients. In many populations worldwide prevalence rates of obesity exceed $20 \%$ in both males and females. The ICD-10 and ICD-11 Beta Draft definitions of obesity do not reflect our current knowledge of this disease; unsystematic definitions entail the possibility that clinicians will not diagnose the respective disease and/or that the diagnosis is deemed clinically irrelevant, thus precluding a patient-oriented focus to address the disease. The listing of overweight and obesity within the parent 'Endocrine, nutritional and metabolic diseases' is not readily compatible with the complexity of obesity; this particularly holds true for the listing 
Hebebrand et al:: A Proposal of the European Association for the Study of Obesity to Improve the ICD-11 Diagnostic Criteria for Obesity Based on the Three Dimensions Etiology, Degree of Adiposity and Health Risk

within the subcategory 'Nutritional diseases'. For this purpose, we suggest that the common disease obesity is listed as an overarching parent category, thus obliterating the need to classify this disease within a biologically and medically misleading context. The definitions of the current Beta Draft are very crude for the overarching parents and become more and more detailed as the respective diagnoses become rarer. The opposite should apply: common diagnoses need to be explained in more detail to allow the clinician to make use of the information to better diagnose and treat patients. The proposed EASO classification aims to overcome the negligence that obesity has had in the past with respect to its diagnosis. Our proposal is based on current knowledge, uses common medical terminology, and allows a clinician to both consider etiological and quantitative aspects. Whereas the classification of different classes of obesity is based on BMI, the definition pays adherence to the necessity to assess adiposity and regional fat distribution. Importantly, we focus on obesity and recommend that 'Preobesity' in the BMI range of $<30 \mathrm{~kg} / \mathrm{m}^{2}$ is included in ICD-11 only if adiposity-related metabolic and/or cardiovascular diseases are manifest in the respective patient. Our definitions repeatedly allude to the age of a patient; a particular BMI in the overweight range is of greater medical concern in a younger than an older patient. Finally, we need to circumvent any ambiguity with respect to our definitions of overweight and obesity; we propose to stick to the categorization proposed by the WHO in 2000 [2], according to which overweight is defined via a BMI $\geq 25 \mathrm{~kg} / \mathrm{m}^{2}$; accordingly, obesity defined via a BMI $\geq 30 \mathrm{~kg} / \mathrm{m}^{2}$ represents a subgroup of overweight associated with a substantially elevated fat mass. EASO perceives the dire need to better anchor the diagnosis of obesity within ICD to benefit patients. EASO recommends that societies as a whole strive to reduce the obesogenic environment and help individuals with obesity overcome stigmatization. Healthcare professionals need to make knowledgeable of our current understanding of obesity to help guide individuals with obesity and to offer warranted diagnostic assessments and treatment.

\section{References}

1 Hebebrand J, Bulik CM: Critical appraisal of the provisional DSM-5 criteria for anorexia nervosa and an alternative proposal. Int J Eat Disord 2011;44:665-678.

2 World Health Organization: Obesity: Preventing and Managing the Global Epidemic. Report of a WHO Consultation(WHO Technical ReportSeries 894).2000.www.who.int/nutrition/publications/obesity/WHO_TRS_894/ en/ (last accessed July 12, 2017).

3 World Health Organization: Constitution of the World Health Organization. 1946. http://apps.who.int/gb/bd/ $P D F / b d 47 / E N /$ constitution-en.pdf?ua=1 (last accessed July 12, 2017).

4 Global Burden of Disease 2015 Obesity Collaborators: Health effects of overweight and obesity in 195 countries over 25 years. N Engl J Med 2017; 377:13-27.

5 Sharma A, Campell-Sherer DL: Redefining obesity: beyond the numbers. Obesity (Silver Spring) 2017;25: 660-661.

6 Nuttall FQ: Body mass index. Obesity, BMI, and health: a critical review. Nutr Today 2015;50:117-128.

7 World Health Organization: ICD 11 Beta Draft (lookup May 31, 2017). 2017. http://apps.who.int/classifications/icd11/browse/f/en (last accessed July 12, 2017).

8 Flegal KM, Panagiotou OA, Graubard BI: Estimating population attributable fractions to quantify the health burden of obesity. Ann Epidemiol 2015;25:201-207.

9 World Health Organization: Obesity and overweight. Fact sheet. Updated June 2016. http://www.who.int/ mediacentre/factsheets/fs311/en/ (last accessed July 12, 2017).

10 Blundell JE, Dulloo AG, Salvador J, Frühbeck G; on behalf of the EASO SAB Working Group on BMI: Beyond BMI - phenotyping the obesities. Obes Facts 2014;7:322-328.

11 Pollack A: AMA recognizes obesity as a disease. New York Times 2013. www.nytimes.com/2013/06/19/ business/ama-recognizes-obesity-as-a-disease.html?ref=health\&_r=2\& (last accessed July 12, 2017).

12 Stoner L, Cornwall J: Did the American Medical Association make the correct decision classifying obesity as a disease? Australas Med J 2014;7:462-464.

13 Sims E: Are there persons who are obese, but metabolically healthy? Metabolism 2001;50:1499-1504. 
Hebebrand et al.: A Proposal of the European Association for the Study of Obesity to Improve the ICD-11 Diagnostic Criteria for Obesity Based on the Three Dimensions Etiology, Degree of Adiposity and Health Risk

14 Global BMI Mortality Collaboration, Di Angelantonio E, Bhupathiraju SHN, et al: Body-mass index and all-cause mortality: individual-participant-data meta-analysis of 239 prospective studies in four continents. Lancet 2016;388:776-786.

15 Stringhini S, Carmeli C, Jokela M, Avendaño M, Muennig P, Guida F, Ricceri F, d'Errico A, Barros H, Bochud M, Chadeau-Hyam M, Clavel-Chapelon F, Costa G, Delpierre C, Fraga S, Goldberg M, Giles GG, Krogh V, Kelly-Irving M, Layte R, Lasserre AM, Marmot MG, Preisig M, Shipley MJ, Vollenweider P, Zins M, Kawachi I, Steptoe A, Mackenbach JP, Vineis P, Kivimäki M; LIFEPATH consortium: Socioeconomic status and the $25 \times 25$ risk factors as determinants of premature mortality: a multicohort study and meta-analysis of $1 \cdot 7$ million men and women. Lancet 2017;389:1229-1237.

16 Visscher TL, Seidell JC: The public health impact of obesity. Annu Rev Public Health 2001;22:355-375.

17 Sharma AM, Kushner RF: A proposed clinical staging system for obesity. Int J Obes (Lond) 2009;33:289-295.

18 Padwal RS, Pajewski NM, Allison DB, Sharma AM: Using the Edmonton obesity staging system to predict mortality in a population-representative cohort of people with overweight and obesity. CMAJ 2011; 183:E1059-1066

19 Frühbeck G, Toplak H, Woodward E, Yumuk V, Maislos M, Oppert JM; Executive Committee of the European Association for the Study of Obesity: Obesity: the gateway to ill health - an EASO position statement on a rising public health, clinical and scientific challenge in Europe. Obes Facts 2013;6:117-120.

20 Hebebrand J: Obesity; in Martin A, Volkmar FR, Lewis M (eds): Lewis's Child and Adolescent Psychiatry: A Comprehensive Textbook. Philadelphia, Lippincott, 2007, pp 607-614.

21 Centers for Disease Control and Prevention: (2015;last year reviewed) Defining Childhood Obesity. Page last updated: October 20, 2016. www.cdc.gov/obesity/childhood/defining.html (last accessed July 12, 2017)..

22 Kromeyer-Hauschild K, Wabitsch M, Kunze D, Geller F, Geiß HC, Hesse V, von Hippel A, Jaeger U, Johnsen D, Korte W, Menner K, Müller G, Müller JM, Niemann-Pilatus A, Remer T, Schaefer F, Wittchen HU, Zabransky S, Zellner K, Ziegler A, Hebebrand J: Percentiles of body mass index in children and adolescents evaluated from different regional German studies (in German). Monatsschr Kinderheilkd 2001;149:80.

23 Cole TJ, Lobstein T: Extended international (IOTF) body mass index cut-offs for thinness, overweight and obesity. Pediatr Obes $2012 ; 7: 284-294$.

24 Hemmelmann C, Brose S, Vens M, Hebebrand J, Ziegler A: Percentiles of body mass index of 18-80-year-old German adults based on data from the Second National Nutrition Survey (in German). Dtsch Med Wochenschr. 2010;135:848-852

25 Stenholm S, Harris TB, Rantanen T, Visser M, Kritchevsky SB, Ferrucci L: Sarcopenic obesity - definition, etiology and consequences. Curr Opin Clin Nutr Metab Care 2008;11:693-700.

26 Palmer BF, Clegg DJ: The sexual dimorphism of obesity. Mol Cell Endocrinol 2015;402:113-119.

27 Pulit SL, Karaderi T, Lindgren CM: Sexual dimorphisms in genetic loci linked to body fat distribution. Biosci Rep. 2017;37:BSR20160184.

28 Hinney A, Kesselmeier M, Jall S, et al: Evidence for three genetic loci involved in both anorexia nervosa risk and variation of body mass index. Mol Psychiatry 2017;22:321-322.

29 Catalano PM, Shankar K: Obesity and pregnancy: mechanisms of short term and long term adverse consequences for mother and child. BMJ 2017;356:j1.

30 Ma RC, Schmidt MI, Tam WH, McIntyre HD, Catalano PM: Clinical management of pregnancy in the obese mother: before conception, during pregnancy, and post partum. Lancet Diabetes Endocrinol 2016;4:10371049.

31 Eisenberg ML, Kim S, Chen Z, Sundaram R, Schisterman EF, Louis GM: The relationship between male BMI and waist circumference on semen quality: data from the LIFE study. Hum Reprod 2014;29:193-200.

32 Rosenbaum M, Leibel RL: 20 years of leptin: role of leptin in energy homeostasis in humans. J Endocrinol 2014; 223:T83-96.

33 Blundell JE, Finlayson G, Gibbons C, Caudwell P, Hopkins M: The biology of appetite control: do resting metabolic rate and fat-free mass drive energy intake? Physiol Behav 2015;152:473-478.

34 Fothergill E, Guo J, Howard L, Kerns JC, Knuth ND, Brychta R, Chen KY, Skarulis MC, Walter M, Walter PJ, Hall KD: Persistent metabolic adaptation 6 years after 'The Biggest Loser' competition. Obesity (Silver Spring) 2016;24:1612-1619.

35 Johns DJ, Hartmann-Boyce J, Jebb SA, Aveyard P; Behavioural Weight Management Review Group: Diet or exercise interventions vs combined behavioral weight management programs: a systematic review and metaanalysis of direct comparisons. J Acad Nutr Diet 2014;114:1557-1568.

36 U.S. Preventive Services Task Force: Draft Recommendation Statement. Obesity in Children and Adolescents: Screening. 2016. www.uspreventiveservicestaskforce.org/Page/Document/draft-recommendationstatement165/obesity-in-children-and-adolescents-screening1 (last accessed July 12, 2017).

37 U.S. Preventive Services Task Force: Obesity in Adults: Screening and Management 2012. www.uspreventiveservicestaskforce.org/Page/Document/UpdateSummaryFinal/obesity-in-adults-screening-andmanagement?ds=1\&s=obesity (last accessed July 12, 2017).

38 Mühlig Y, Wabitsch M, Moss A, Hebebrand J: Weight loss in children and adolescents. Dtsch Arztebl Int 2014;;111:818-824.

39 Swinburn BA, Sacks G, Hall KD, McPherson K, Finegood DT, Moodie ML, Gortmaker SL: The global obesity pandemic: shaped by global drivers and local environments. Lancet 2011;378:804-814. 
Hebebrand et al.: A Proposal of the European Association for the Study of Obesity to Improve the ICD-11 Diagnostic Criteria for Obesity Based on the Three Dimensions Etiology, Degree of Adiposity and Health Risk

40 Gloy VL, Briel M, Bhatt DL, Kashyap SR, Schauer PR, Mingrone G, Bucher HC, Nordmann AJ: Bariatric surgery versus non-surgical treatment for obesity: a systematic review and meta-analysis of randomised controlled trials. BMJ 2013;347:f5934.

41 Nguyen NT, Varela JE: Bariatric surgery for obesity and metabolic disorders: state of the art. Nat Rev Gastroenterol Hepatol 2017;14:160-169.

42 Fouse T, Brethauer S: Resolution of comorbidities and impact on longevity following bariatric and metabolic surgery. Surg Clin North Am 2016;96:717-732.

43 Fried M, Yumuk V, Oppert JM, Scopinaro N, Torres AJ, Weiner R, Yashkov Y, Frühbeck G; European Association for the Study of Obesity; International Federation for the Surgery of Obesity - European Chapter: Interdisciplinary European guidelines on metabolic and bariatric surgery. Obes Facts 2013;6:449-468.

44 Puhl R., Heuer C: The stigma of obesity: a review and update. Obesity (Silver Spring) 2009;17:941-964.

45 Flint S: Obesity stigma: prevalence and impact in healthcare, Br J Obes 2015;1:1-40.

46 Nan C, Guo B, Warner C, Fowler T, Barrett T, Boomsma D, Nelson T, Whitfield K, Beunen G, Thomis M, Maes $\mathrm{HH}$, Derom C, Ordoñana J, Deeks J, Zeegers M: Heritability of body mass index in pre-adolescence, young adulthood and late adulthood. Eur J Epidemiol 2012;27:247-253.

47 Locke AE, Kahali B, Berndt SI, et al: Genetic studies of body mass index yield new insights for obesity biology. Nature 2015;518:197-206.

48 Dempfle A, Hinney A, Heinzel-Gutenbrunner M, Raab M, Geller F, Gudermann T, Schäfer H, Hebebrand J: Large quantitative effect of melanocortin-4 receptor gene mutations on body mass index. J Med Genet 2004;41: 795-800.

49 Farooqi IS, O’Rahilly S: 20 years of leptin: human disorders of leptin action. J Endocrinol 2014;223:T63-70.

50 Dinsa GD, Goryakin Y, Fumagalli E, Suhrcke M: Obesity and socioeconomic status in developing countries: a systematic review. Obes Rev 2012;13:1067-1079.

51 Wang Y, Lim H: The global childhood obesity epidemic and the association between socio-economic status and childhood obesity. Int Rev Psychiatry 2012;24:176-188.

52 World Health Organization: Obesity and other hyperalimentation (E65-E68). 1992. http://apps.who.int/classifications/icd10/browse/2016/en\#/E65-E68 (last accessed July 2017).

53 Whitaker RC, Wright JA, Pepe MS, Seidel KD, Dietz WH. Predicting obesity in young adulthood from childhood and parental obesity. N Engl J Med 1997;337:869-873.

54 Wabitsch M, Funcke JB, Lennerz B, Kuhnle-Krahl U, Lahr G, Debatin KM, Vatter P, Gierschik P, Moepps B, Fischer-Posovszky P: Biologically inactive leptin and early-onset extreme obesity. N Engl J Med 2015;372: 48-54.

55 Allison DB, Downey M, Atkinson RL, Billington CJ, Bray GA, Eckel RH, Finkelstein EA, Jensen MD, Tremblay A: Obesity as a disease: a white paper on evidence and arguments commissioned by the Council of the Obesity Society. Obesity (Silver Spring) 2008;16:1161-1177. 